\title{
EFEITO DA MOAGEM DE ALTA INTENSIDADE E DA IRRADIAÇÃO GAMA SOBRE A LIBERAÇÃO DE POTÁSSIO DA MOSCOVITA
}

\author{
Adalberto Leles de Souza ${ }^{1}$, Fernando Soares Lameiras ${ }^{2}$
}

\begin{abstract}
RESUMO
O Brasil tem uma grande e crescente dependência de importação de potássio para uso na agricultura. O desenvolvimento de fontes alternativas de potássio tem importância estratégica. A moagem de rochas ricas em potássio estrutural e que ocorrem em várias regiões do País é uma possibilidade que deve ser considerada, porque a menor granulometria acelera o processo de liberação do potássio. O objetivo deste trabalho foi estudar o efeito da moagem de alta intensidade e da irradiação gama sobre a taxa de liberação de potássio da moscovita. Observou-se que é possível obter granulometria na faixa de 10 a $11 \mu \mathrm{m}$ por meio de moagem com um moinho planetário de alta intensidade a 800 rotações por minuto durante 6 horas. As amostras moídas nessas condições apresentaram uma taxa de liberação de potássio duas vezes mais alta que uma amostra pulverizada por meio de moagem convencional com uma granulometria de $92 \mu \mathrm{m}$. Não se observou efeito da irradiação gama até uma dose de 600 kGy.
\end{abstract}

Palavras-chave: potássio, liberação, moscovita, moagem de alta intensidade

\section{ABSTRACT \\ EFFECT OF THE HIGH ENERGY MILLING AND GAMMA IRRADIATION ON THE RELEASE OF POTASSIUM FROM MUSCOVITE}

Brazil has a large and growing dependence on imports of potassium for use in agriculture. The development of potassium alternative sources has strategic importance. The grinding of rocks rich in structural potassium occurring in various regions of the country should be considered as a possibility, because the finer particles has shown accelerate the release of potassium. The objective of this paper was to investigate the effect of high energy milling and gamma irradiation on the rate of release of potassium from muscovite. It was observed that it is possible to obtain a particle size ranging from 10 to $11 \mu \mathrm{m}$ by grinding with a planetary mill of high energy at 800 revolutions per minute for 6 hours. The ground samples in these conditions showed a rate of potassium release two times higher than a sample pulverized by conventional grinding with a particle size of $92 \mu \mathrm{m}$. No effect of gamma irradiation until $600 \mathrm{kGy}$ dose

Keywords: potassium, release, muscovite, high intensity milling

\section{Recebido para publicação em 16/05/2011. Aprovado em 27/09/2012.}

1- Químico, Mestre em Ciência e Tecnologia das Radiações, Minerais e Materiais CDTN/Belo Horizonte-MG, adalbertoleles@yahoo.com.br 2- Físico, Doutor em Engenharia Metalúrgica, Pesquisador do CDTN/Belo Horizonte-MG, fsl@cdtn.br 


\section{INTRODUÇ̃̃O}

O potássio representa 2,6\% dos elementos químicos que constituem a crosta terrestre. Devido à sua alta reatividade, ele não é encontrado na forma elementar. Vários minerais contêm potássio (BARTHELMY, 2010), com teores variando entre $0,03 \%$ a $67 \%$. A silvita $(\mathrm{KCl}$, com teor de potássio de $52,45 \%)$ e a carnalita $\left(\mathrm{KCl} \cdot \mathrm{MgCl}_{2} \cdot \mathrm{H}_{2} \mathrm{O}\right.$, com teor de potássio de $14,07 \%$ ) são os principais minérios de potássio. Ele é utilizado em vários setores industriais, como cerâmicas, fertilizantes, produtos químicos e farmacêuticos. Porém, 95\% da produção mundial de potássio são direcionados para a indústria de fertilizantes na forma de cloreto e sulfato de potássio.

O Brasil tem a oitava maior reserva de potássio, sendo o Canadá e a Rússia os países detentores das maiores reservas. A reserva brasileira é de 13 bilhões de toneladas na forma de silvita e carnalita, localizadas nos estados de Sergipe e do Amazonas. A mina de Taquari-Vassouras, a única produtora de cloreto de potássio no Brasil, está localizada em Rosário do Catete - SE, sob responsabilidade da VALE, que está produzindo a plena carga. Estimase que o encerramento da explotação do potássio nesta mina se dará em 2016 (OLIVEIRA, 2009). Importantes depósitos de carnalita, no Sergipe, estão em avaliação pela VALE, com o projeto de uma planta de extração de potássio previsto para operação a partir de 2014, que terá uma produção estimada em 1,2 milhão de toneladas métricas de potássio (VALE, 2010).

As reservas brasileiras de potássio mineráveis são reduzidas. Em 2008, a produção brasileira de potássio supriu apenas $8,7 \%$ do consumo. O restante foi importado do Canadá (33\%), Bielorússia (29\%), Alemanha (13\%), Israel (12\%) e Rússia (11\%). Há um significativo aumento do custo de importação do cloreto de potássio nos últimos anos (OLIVEIRA, 2009).

O potássio é um importante nutriente dos fertilizantes utilizados nos solos brasileiros. Ele atua nas plantas na síntese de proteínas, na ativação de coenzimas, regula a pressão osmótica e auxilia os mecanismos de transporte de amido e açúcar. Em geral, o crescimento lento e a baixa qualidade de frutos e dos grãos são indicativos da nutrição inadequada de potássio (GHOSH et al., 1995, MALLARINO \& HIHASHI, 2009, MORSHED et al. 2009). Nos solos, o potássio é encontrado em quatro formas diferentes: o potássio em solução, trocável, fixado e estrutural (FOTH, 1990).

A importância da produção agrícola para a economia brasileira (alimentos e biocombustíveis), associada ao aumento da demanda mundial por commodities agrícolas, torna essa dependência externa do fornecimento de potássio uma das maiores fragilidades estratégicas do País. É muito importante investigar fontes alternativas para o suprimento de potássio para a agricultura brasileira. As fontes alternativas têm as seguintes vantagens (MARTINS et al., 2010): (i) A grande abundância e a ocorrência bem distribuída no território brasileiro permitem a utilização regional das fontes alternativas, da mesma forma que o calcário agrícola; (ii) A baixa solubilidade das fontes alternativas racionaliza o uso de nutrientes pelas plantas e diminui, em médio e longo prazos, a necessidade de utilização de nutrientes solúveis pelo aumento sustentável da fertilidade do solo e o efeito residual; (iii) $\mathrm{O}$ baixo custo de produção e a simplicidade do processo produtivo permitem o desenvolvimento de uma mineração de pequeno porte, da mesma forma que as produtoras de calcário agrícola; (iv) A elevada complexidade composicional é caracterizada por uma diversidade de minerais em diferentes proporções e permite a recuperação gradual da fertilidade do solo pelo intemperismo desses mesmos minerais; (v) $\mathrm{O}$ efeito condicionador do solo é produto da formação de novas fases minerais com elevada superfície específica e carga superficial, derivadas do intemperismo dos minerais primários.

Entre as fontes alternativas de potássio, destacam-se os feldspatos ortoclásio e microclina, com teores de $\mathrm{K}_{2} \mathrm{O}$ de $19,2 \%$. As micas, que apresentam teores de $\mathrm{K}_{2} \mathrm{O}$ da ordem de $11 \%$, também se apresentam como fontes alternativas para a produção de sais de potássio ou como fertilizantes para liberação gradual de íons de potássio. Por exemplo, a capacidade de fornecimento de potássio após a moagem das rochas biotita xisto, brecha alcalina e ultramáfica alcalina, com teores de $\mathrm{K}_{2} \mathrm{O}$ variando entre 2 a 5\%, foi suficiente para o crescimento inicial de milho e

\section{REVENG} 501-511p. 
melhoraram a capacidade condicionadora do solo (RESENDE et al., 2006).

A moscovita é um mineral pertencente ao grupo dos filossilicatos. A sua estrutura é formada pela sobreposição de duas unidades básicas: as camadas tetraédricas e as camadas octaédricas. As camadas tetraédricas são formadas por tetraedros de $\mathrm{SiO}_{4}^{4}$, constituídos por quatro átomos de oxigênio ou hidroxilas coordenados por um átomo de silício. Cada tetraedro $\mathrm{SiO}_{4}^{4-}$ compartilha três dos seus quatro átomos de oxigênio com tetraedros vizinhos, formando uma rede hexagonal que se repete indefinidamente e dá origem à camada tetraédrica. A camada octaédrica se consiste de duas folhas de oxigênios ou hidroxilas densamente compactadas com as quais átomos de alumínio formam coordenação octaédrica.

A junção das camadas octaédricas (o) e tetraédrica (t) é feita pelo compartilhamento dos oxigênios ou hidroxilas apicais para formar os minerais, como, por exemplo, a caolinita, denominados 1:1 ou t-o ou os minerais $2: 1$ ou t-o-t, como a moscovita. A composição e o arranjo das camadas octaédricas e tetraédricas determinam as propriedades físicas e químicas apresentadas pelos minerais do grupo dos filossilicatos. Na moscovita, o potássio se encontra entre as duas camadas t-o-t, exercendo duas funções. Uma delas está relacionada com o equilíbrio de cargas elétricas entre as camadas, que são carregadas negativamente. É o potássio que mantém as camadas unidas. A outra está relacionada com a compensação de carga elétrica por causa da substituição do silício pelo alumínio nos tetraedros. O silício tem valência 4+, enquanto o alumínio tem valência 3+. Quando um alumínio se encontra no centro de um tetraedro, é necessário que um íon positivo monovalente esteja nas proximidades para neutralização da carga elétrica.

O potássio presente na moscovita é classificado como potássio estrutural e a sua disponibilização ocorre principalmente por meio de intemperismo. Uma maneira de aumentar a taxa de liberação do potássio pela moscovita é diminuir o tamanho da partícula de moscovita. A moscovita é usualmente processada até granulometrias entre 40 e $60 \mu \mathrm{m}$. Com a moagem de alta intensidade é possível obter granulometrias inferiores a $10 \mu \mathrm{m}$. Nessa faixa de granulometria espera-se um substancial aumento da taxa de liberação de potássio pelo intemperismo, devido à mais alta superfície das partículas. Outra maneira pode ser proporcionada pela irradiação da moscovita com radiação ionizante de alta energia, como raios gama ou feixe de elétrons.

O processo de liberação pela radiação seria parecido com aquele que se observa na formação da cor no quartzo natural (NUNES et al., 2009). Os tetraedros que possuem alumínio formam uma estrutura representada por $\left[\mathrm{Al}_{\mathrm{Si}} \mathrm{O}_{4} / \mathrm{K}^{+}\right]$, onde $\mathrm{Al}_{\mathrm{Si}}$ representa um alumínio num sítio de silício (o centro do tetraedro) e $\mathrm{K}^{+}$representa o íon de potássio que fica nas proximidades para compensação de carga. Um fóton gama ou um elétron de alta energia é capaz de ejetar um elétron das nuvens eletrônicas dos oxigênios do tetraedro, que passam a ter um buraco eletrônico, representado por $\mathrm{h}^{+}$. Com esse buraco eletrônico, o potássio não necessita mais exercer a sua função de compensador de carga e fica livre para difundir na rede cristalina da moscovita. Essa reação pode ser representada por:

$\left[\mathrm{Al}_{\mathrm{Si}} \mathrm{O}_{4} / \mathrm{K}^{+}\right]+\gamma \rightarrow\left[\mathrm{Al}_{\mathrm{Si}} \mathrm{O}_{4} / \mathrm{h}^{+}\right]+\mathrm{K}^{+}+\mathrm{e}^{-}$

em que

$\gamma=$ um fóton de raio gama ou um elétron do feixe de elétrons; e

$\mathrm{e}^{-}=$um elétron preso numa posição intersticial na estrutura cristalina da moscovita.

Espera-se que uma moscovita irradiada apresente uma maior taxa de liberação de potássio. Nesse caso, parte do potássio presente na moscovita se tornaria potássio fixado.

O objetivo deste trabalho foi investigar o efeito de baixas granulometrias, obtidas por moagem de alta intensidade, e da exposição à radiação ionizante sobre a liberação de potássio pela moscovita.

\section{MATERIAL E MÉTODOS}

As amostras foram fornecidas pela Lamil Lage Minérios Ltda. Eram constituídas por blocos formados por várias placas de moscovita e inclusões de outros minerais. Os blocos foram britados em um britador de mandíbulas e de disco. Em seguida, o material britado foi lavado e o material de hábito 
lamelar foi selecionado e moído num moinho de disco. A pulverização foi feita num pulverizador com uso de panela, aro e soquete de aço inoxidável durante 5 minutos. O material pulverizado foi homogeneizado, quarteado e armazenado em frações de $100 \mathrm{~g}$. A Figura 1 ilustra o procedimento de preparo da amostra.

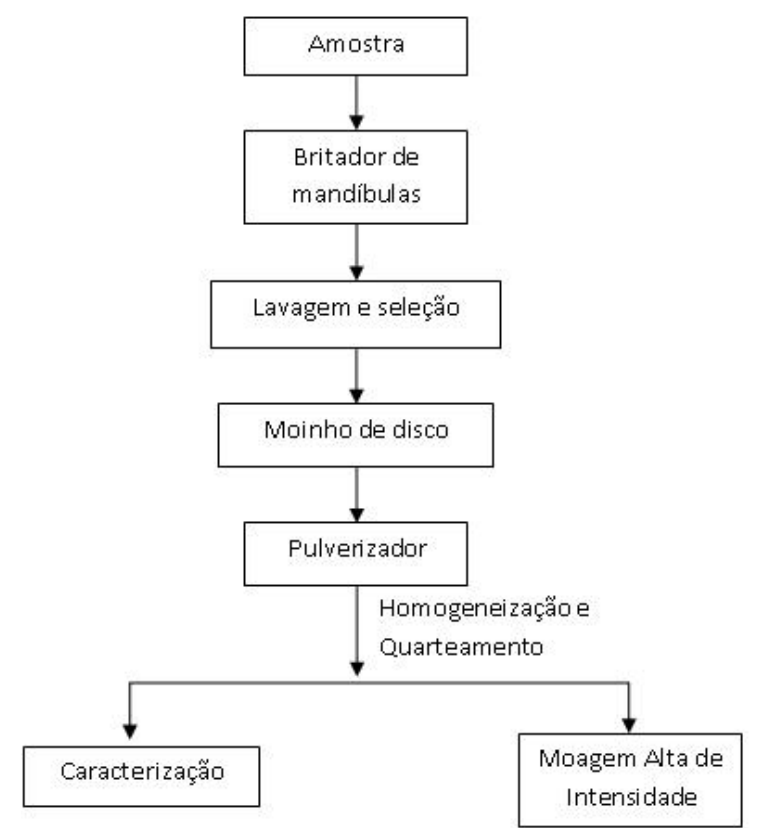

Figura 1. Fluxograma do preparo de amostra

As identificações das fases minerais presentes nas amostras foram realizadas por meio de difração de raios $\mathrm{X}$ (método do pó). Foi utilizado um difratômetro marca Rigaku modelo D $\backslash$ MAX Última automático, equipado com tubo de raios $\mathrm{X}$ de cobre. Os difratogramas foram comparados com o banco de dados da International Center For Diffraction Data (ICCD) com auxílio do programa Crystallographica Search_Match $2,0,2,0$.

Os teores de silício e alumínio foram obtidos por meio de análise gravimetria. Os teores de potássio e ferro foram obtidos por meio de ativação neutrônica, com as irradiações realizadas no reator nuclear TRIGA MARK IPR-R1 do CDTN - Centro de Desenvolvimento da Tecnologia Nuclear. O potássio em solução foi quantificado por espectrometria de emissão atômica e os teores de ferro, silício e alumínio foram determinados por espectrometria de emissão atômica por plasma indutivamente acoplado (ICP/AES).

A distribuição granulométrica do material foi obtida por meio de peneiramento a seco em uma série de peneiras de diferentes aberturas da série Tyler. Para tamanhos de partículas menores que $300 \mu \mathrm{m}$ e para o material obtido por meio de moagem de alta intensidade, a análise granulométrica foi realizada por meio da difratometria a laser com o equipamento CILAS modelo 1064 em meio aquoso, após a exposição ao ultrassom durante $60 \mathrm{~s}$ e sem a presença de dispersante.

A moagem de alta intensidade foi realizada utilizando um moinho de bolas do tipo planetário, projetado e construído pelo CDTN (Figura 2).

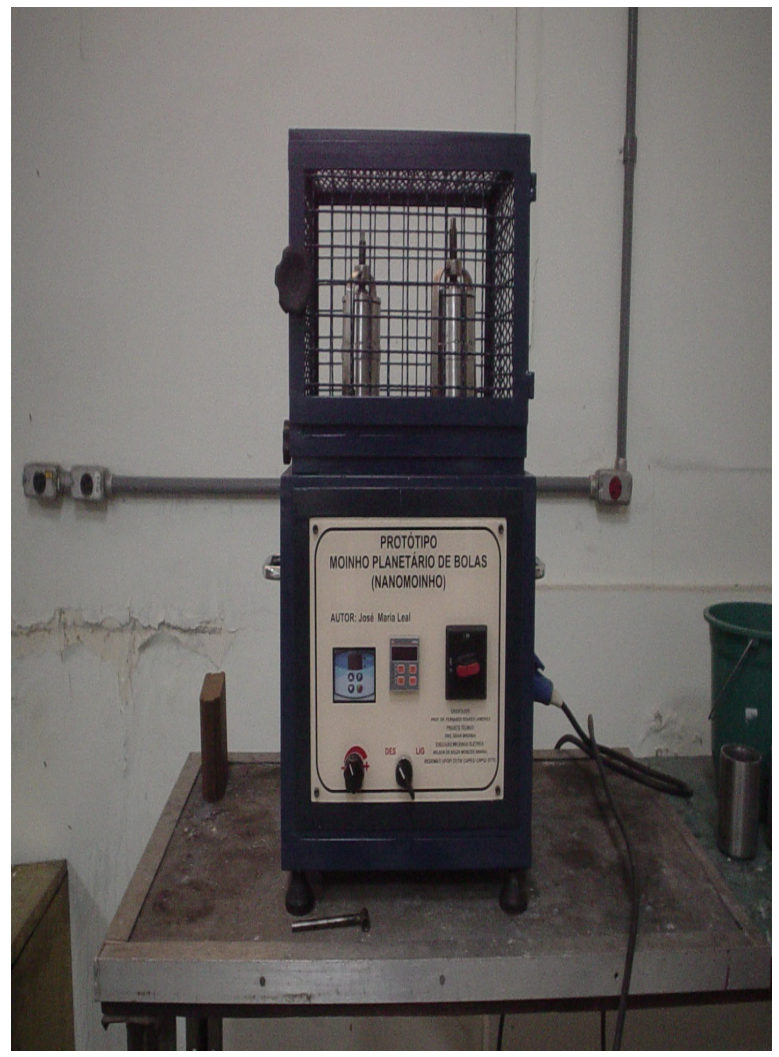

Figura 2. Moinho planetário de bolas de alta intensidade utilizado neste trabalho.

Esse moinho consiste de quatro copos cilíndricos de aço inoxidável com capacidade de $150 \mathrm{~mL}$ cada, distribuídos em dois conjuntos, onde um copo fica sobre o outro. Os conjuntos ficam diametralmente posicionados e possuem movimentos simultâneos de rotação e translação. A moagem em alta intensidade foi realizada utilizando material

\section{REVENG 501-511p.}

ENGENHARIA NA AGRICULTURA, VIÇOSA - MG, V.20 N.6, NOVEMBRO / DEZEMBRO 2012 
pulverizado. As moagens foram conduzidas em via úmida mantendo-se fixa a porcentagem de sólidos em 20\%. Foram utilizadas $80 \mathrm{~g}$ de carga de bolas de alumina como corpo moedor e distribuição de tamanho de $70 \%$ com diâmetro médio de 15 mm e $30 \%$ com diâmetro médio de 18 mm. A avaliação da influência dos parâmetros de moagem foi feita de acordo com um planejamento fatorial $2^{2}$ composto central, conforme mostrado no Quadro 2. Foram analisadas duas respostas: o diâmetro médio das partículas e o desgaste do corpo moedor, calculado com base na relação entre a diferença de massa inicial e final das bolas.

Após a moagem de alta intensidade, as amostras foram irradiadas com raios gama no Laboratório de Irradiação Gama do Centro de Desenvolvimento da Tecnologia Nuclear, por meio do irradiador gama modelo GB-127 e tipo IR-214 da MSD Nordion equipado com uma fonte de ${ }^{60} \mathrm{Co}$. As amostras foram irradiadas até doses de 300 kGy e 600 kGy.

Para verificar a influência da moagem de alta intensidade e da dose de irradiação gama na liberação de potássio da moscovita, foi utilizado um planejamento composto central de face centrada. Os fatores com os seus níveis estão apresentados no Quadro 3.

A extração de íons potássio foi realizada por meio de resina de troca iônica. O procedimento de pré-condicionamento, preparação e recuperação da resina foi o mesmo sugerido por Silva (2009). Para a extração de íons da moscovita, foram pesados cerca de $1 \mathrm{~g}$ de moscovita em um frasco plástico. Em seguida foram adicionados 25,0 mL de água deionizada e $2,5 \mathrm{~mL}$ de mistura de resina catiônica e aniônica. O frasco foi então fechado e mantido em um agitador com movimento circular-horizontal à velocidade de $220 \mathrm{rpm}$ por 16 horas. Após esse período, a suspensão de resina e moscovita foi peneirada e lavada com o mínimo possível de água para retirar toda a moscovita. Em seguida a resina foi transferida para um recipiente de $100 \mathrm{~mL}$ usando $50,00 \mathrm{~mL}$ de solução de $\mathrm{NH}_{4} \mathrm{Cl}$ 0,8 mol. $\mathrm{L}^{-1}$ e $50,00 \mathrm{~mL}$ de solução de $\mathrm{HCl} 0,2$ mol.L ${ }^{-1}$. A suspensão ficou em repouso por cerca de 30 minutos para permitir a liberação de gás carbônico. Em seguida, os frascos foram agitados por uma hora a $220 \mathrm{rpm}$. Após esse tempo, a resina foi peneirada e o extrato foi encaminhado para as determinações de potássio, alumínio e ferro.

\section{RESULTADOS E DISCUSSÃO}

A análise química das amostras revelou a presença de 44,5\% de $\mathrm{SiO}_{2}, 37,4 \%$ de $\mathrm{Al}_{2} \mathrm{O}_{3}$, $10,12 \%$ de $\mathrm{K}_{2} \mathrm{O}, 1,6 \%$ de $\mathrm{Fe}_{2} \mathrm{O}_{3}$ e perda ao fogo de $5,0 \%$. Os difratogramas revelaram que a moscovita era a fase predominante. A amostra pulverizada apresentou um diâmetro médio de partícula de $92 \mu \mathrm{m}$.

O planejamento fatorial $2^{2}$ envolveu duas réplicas para as quatro combinações e quatro réplicas no ponto central. O Quadro 4 mostra os resultados obtidos.

O Quadro 5 mostra a análise de variância (ANOVA) para o diâmetro médio com nível de confiança de 95\%. Essa análise revela que o tempo de moagem e a rotação influenciam o diâmetro médio final das partículas de moscovita maneira significativa $(\mathrm{p}<0,05)$. Observa-se também que não há interação significativa $(\mathrm{p}>0,05)$ entre o tempo de moagem e a rotação.

Quadro 2. Planejamento fatorial 22 para a moagem de alta intensidade.

\begin{tabular}{cccc}
\hline Fatores da moagem & Nível baixo (-1) & Nível central (0) & Nível alto (+1) \\
\hline Tempo $(\mathrm{h})$ & 2 & 4 & 6 \\
Rotação $(\mathrm{rpm})$ & 400 & 600 & 800 \\
\hline
\end{tabular}

Quadro 3. Planejamento composto central de face centrada para o estudo da influência sobre a liberação do potássio pela moscovita

\begin{tabular}{cccc}
\hline Fatores & Nível baixo (-1) & Nível central (0) & Nível alto (+1) \\
\hline Tempo de moagem $(\mathrm{h})$ & 2 & 4 & 6 \\
Rotação $(\mathrm{rpm})$ & 400 & 600 & 800 \\
Dose $(\mathrm{kGy})$ & 0 & 300 & 600 \\
\hline
\end{tabular}


Quadro 4. Resultados do planejamento fatorial $2^{2}$ com ponto central para o efeito da moagem de alta intensidade

\begin{tabular}{ccccc}
\hline $\begin{array}{c}\text { Ensaio } \\
\text { número }\end{array}$ & Tempo (A) & Rotação $(\mathbf{B})$ & Diâmetro médio $(\boldsymbol{\mu m})$ & Desgaste $(\mathbf{\%})$ \\
\hline 1 & -1 & -1 & 64,85 & 0,04 \\
2 & +1 & -1 & 43,67 & 0,36 \\
3 & -1 & +1 & 25,75 & 3,95 \\
4 & +1 & +1 & 10,38 & 15,33 \\
5 & -1 & -1 & 55,77 & 0,17 \\
6 & +1 & -1 & 52,45 & 0,29 \\
7 & -1 & +1 & 22,95 & 3,96 \\
8 & +1 & +1 & 10,89 & 15,11 \\
9 & 0 & 0 & 12,96 & 3,57 \\
10 & 0 & 0 & 14,51 & 3,57 \\
11 & 0 & 0 & 17,71 & 2,87 \\
12 & 0 & 0 & 16,43 & 3,61 \\
\hline
\end{tabular}

Quadro 5. Análise de variância para os efeitos sobre o diâmetro médio

\begin{tabular}{cccccc}
\hline $\begin{array}{c}\text { Fonte de } \\
\text { variação }\end{array}$ & $\begin{array}{c}\text { Graus de } \\
\text { liberdade }\end{array}$ & $\begin{array}{c}\text { Soma dos } \\
\text { quadrados }\end{array}$ & $\begin{array}{c}\text { Média dos } \\
\text { quadrados }\end{array}$ & $\mathbf{F}_{\mathbf{0}}$ & $\mathbf{p}$ \\
\hline Tempo (A) & 1 & 337,09 & 337,09 & 24,34 & 0,002 \\
Rotação (B) & 1 & 2692,68 & 2692,68 & 194,40 & 0,000 \\
AxB & 1 & 1,07 & 1,07 & 0,08 & 0,789 \\
Curvatura & 1 & 1113,71 & 1113,71 & 80,40 & 0,000 \\
Erro & 7 & 96,96 & 13,85 & & \\
Total & 7 & 4241,51 & & & \\
\hline
\end{tabular}

A Figura 3 mostra o diagrama das médias das respostas do diâmetro médio das partículas de moscovita para as combinações de níveis da rotação e do tempo de moagem. Pode-se concluir que o efeito do aumento do tempo de moagem provoca uma redução média do diâmetro das partículas de moscovita de $12,98 \mu \mathrm{m}$. Já o efeito do aumento da rotação é mais pronunciado, pois produz uma redução média do diâmetro de 36,69 $\mu \mathrm{m}$. A menor granulometria foi obtida com a moagem de 6 horas e rotação de $800 \mathrm{rpm}$ (vide Figura 4). Esses resultados indicam, também, uma curvatura da superfície de resposta, ou seja a redução do diâmetro é maior quanto se vai de (-1,1) para $(0,0)$ do que de $(0,0)$ para $(+1,+1)$.

$\mathrm{Na}$ moagem de alta intensidade com o moinho de bolas planetário, operam os modos de moagem relacionados com impacto, predominante no estágio inicial, compressão, predominante no estágio intermediário, e cisalhamento, predominante no estágio final. $\mathrm{O}$ aumento da rotação provoca impactos, compressões e cisalhamentos mais altos, que se revelou mais eficiente que o aumento do tempo de moagem. Para a moscovita, devido à sua estrutura lamelar, não se espera uma boa eficiência do cisalhamento. Isso indica que, para se obter granulometrias menores, o aumento da rotação é mais eficiente que o aumento do tempo de moagem.

O Quadro 6 mostra a análise de variância (ANOVA) para o desgaste com nível de confiança de $95 \%$. Nota-se que o tempo, a rotação e interação entre esses fatores são significativos $(\mathrm{p}<0,05)$.

A Figura 5 mostra os resultados do desgaste médio do corpo moedor durante a moagem de alta intensidade. Pode-se observar que o aumento do tempo de moagem acarreta num maior desgaste e esse aumento depende da rotação, sendo maior para rotações mais altas. O maior desgaste foi observado para o tempo de 6 horas e rotação de 
$800 \mathrm{rpm}$. A curvatura é significativa, ou seja, o aumento do desgaste é muito maior quando se move de $(0,0)$ para $(+1,+1)$ do que de $(-1,-1)$ para $(0,0)$. O desgaste provoca contaminação da moscovita com alumina, material dos corpos moedores, ferro e outros elementos de liga dos copos do moinho.

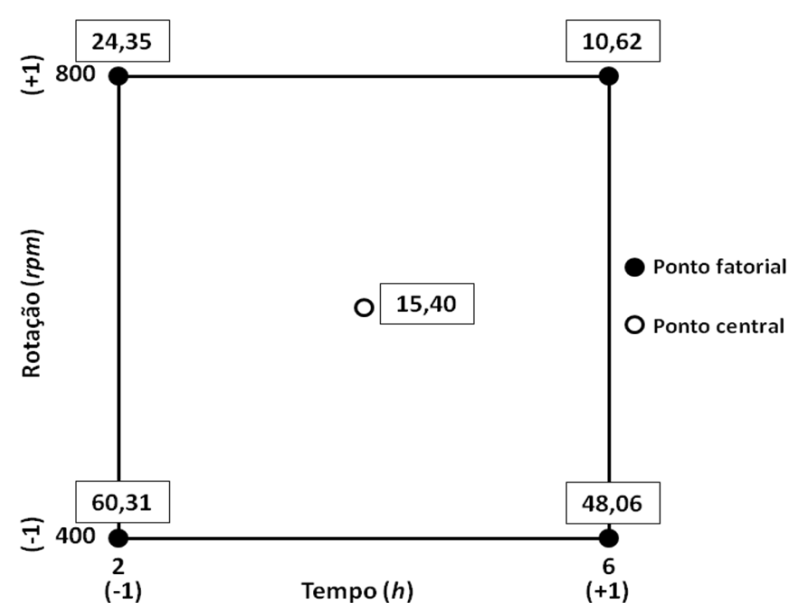

Figura 3. Representação dos resultados de moagem para o diâmetro médio $(\mu \mathrm{m})$.

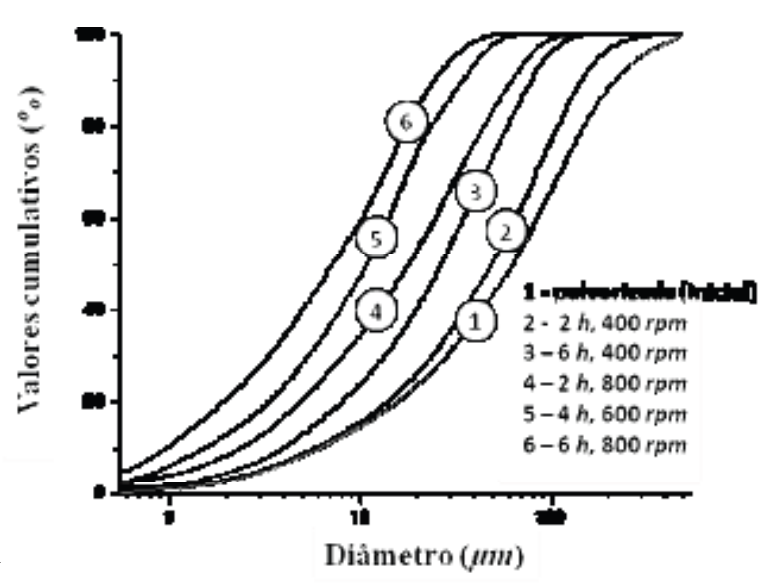

moída.

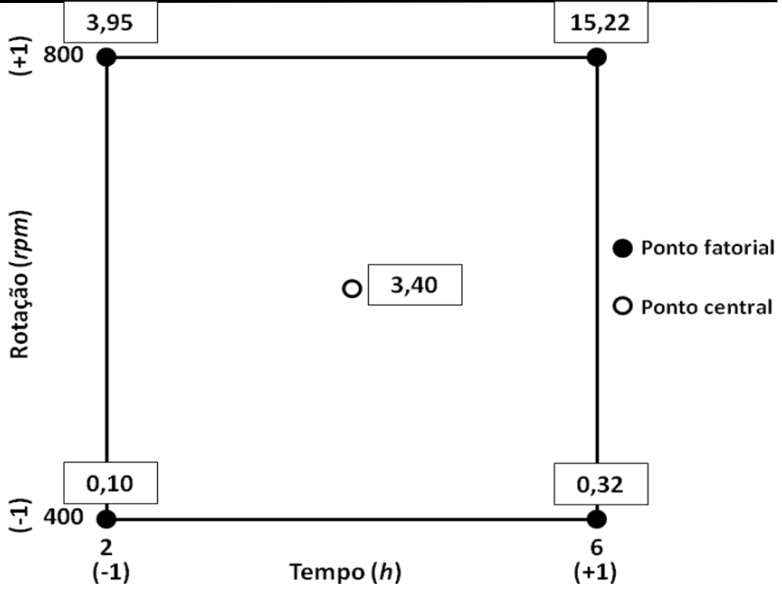

Figura 5. Representação dos resultados de moagem para o desgaste $(\%)$.

Os difratogramas de raios $\mathrm{X}$ das amostras moídas revelaram que a moagem de alta intensidade não provocou mudanças significativas na estrutura da moscovita. O aumento da largura dos picos foi atribuído à delaminação e à redução do tamanho dos grãos da moscovita. Notou-se também o aparecimento de novas reflexões, que foram atribuídas à contaminação da moscovita com alumina $\left(\mathrm{Al}_{2} \mathrm{O}_{3}\right)$ causada pelo desgaste do corpo moedor. Os desgastes do copo do moinho (feito de aço inoxidável) e do corpo moedor são maiores para rotações altas e tempos de moagem longos, como ficou evidenciado pelos resultados das análises químicas das amostras moídas, apresentadas no Quadro 7, onde se observa o aumento dos teores de $\mathrm{Al}_{2} \mathrm{O}_{3}$ e de $\mathrm{Fe}_{2} \mathrm{O}_{3}$ com o aumento do tempo e da rotação da moagem.

O Quadro 8 apresenta o resultado do planejamento fatorial $2^{3}$ composto central, onde foram executados 18 experimentos para verificação da influência do tempo de moagem $(\mathrm{A})$, da rotação (B) e da dose (C) sobre a extração de íons de potássio determinada pelo método da resina de troca

Quadro 6. Análise de variância para os efeitos sobre o desgaste

\begin{tabular}{cccccc}
\hline $\begin{array}{c}\text { Fonte de } \\
\text { variação }\end{array}$ & $\begin{array}{c}\text { Graus de } \\
\text { liberdade }\end{array}$ & $\begin{array}{c}\text { Soma dos } \\
\text { quadrados }\end{array}$ & $\begin{array}{c}\text { Média dos } \\
\text { quadrados }\end{array}$ & $\mathbf{F}_{\mathbf{0}}$ & $\mathbf{p}$ \\
\hline Tempo (A) & 1 & 65,953 & 65,953 & 1104,87 & 0,000 \\
Rotação (B) & 1 & 175,688 & 175,688 & 2943,19 & 0,000 \\
AxB & 1 & 60,996 & 60,996 & 1021,83 & 0,000 \\
Curvatura & 1 & 5,970 & 5,970 & 100,01 & 0,000 \\
Erro & 7 & 0,418 & 0,060 & & \\
Total & 7 & 309,024 & & & \\
\hline
\end{tabular}


iônica. O Quadro 9 apresenta a análise de variância (ANOVA) com nível de confiança de $95 \%$. Nota-se que o tempo de moagem e a rotação influenciam a liberação de potássio $(\mathrm{p}<0,05)$. Há interação significativa entre o tempo e rotação de moagem. A dose de irradiação não influencia a liberação de íons de potássio.

A máxima extração de potássio foi de 11,2\% para tempo de moagem de 6 horas e rotação de $800 \mathrm{rpm}$. A moscovita pulverizada liberou 5,80\% de potássio. Observa-se que a liberação de potássio praticamente dobrou com a utilização da moagem de alta intensidade.

As curvas de superfície, mostradas na Figura 6, permitem uma melhor visualização dos efeitos da dose, do tempo de moagem e da rotação sobre a porcentagem de potássio extraída da moscovita.
Observa-se que o aumento da dose de irradiação não altera significativamente o perfil das três superfícies. Esse fato está de acordo com o Quadro 9. Entretanto, é possível notar que a extração de potássio aumenta com o aumento do tempo de moagem e da rotação. Esse fato pode ser explicado pela diminuição da granulometria das partículas. Observou-se que o diâmetro médio das partículas elevado ao quadrado está relacionado com a porcentagem extraída de potássio por meio da relação:

$y=36,1 \cdot x^{-0,57}$

em que

$\mathrm{y}=$ extração de potássio (\%) e $\mathrm{x}$ é o diâmetro médio $(\mu \mathrm{m})$, conforme mostrado na Figura 7.

Quadro 7. Resultado das análises químicas das amostras moídas

\begin{tabular}{cccccc}
\hline Amostra & $\mathbf{\%} \mathbf{S i O}_{\mathbf{2}}$ & $\mathbf{\%} \mathbf{A l}_{\mathbf{2}} \mathbf{O}_{\mathbf{3}}$ & $\mathbf{\%} \mathbf{K}_{\mathbf{2}} \mathbf{O}$ & $\mathbf{\%} \mathbf{F e}_{\mathbf{2}} \mathbf{O}_{\mathbf{3}}$ & Perda ao fogo \\
\hline Pulverizada & 44,5 & 37,4 & 10,1 & 1,6 & 5,0 \\
$2 \mathrm{~h}, 400 \mathrm{rpm}$ & 48,8 & 35,1 & 9,3 & 1,9 & 4,4 \\
$4 \mathrm{~h}, 600 \mathrm{rpm}$ & 43,1 & 40,2 & 8,0 & 4,3 & 3,3 \\
$6 \mathrm{~h}, 400 \mathrm{rpm}$ & 48,3 & 35,5 & 9,2 & 2,1 & 4,2 \\
$2 \mathrm{~h}, 800 \mathrm{rpm}$ & 41,5 & 42,0 & 7,8 & 4,9 & 2,9 \\
$6 \mathrm{~h}, 800 \mathrm{rpm}$ & 29,7 & 49,5 & 4,9 & 10,1 & - \\
$6 \mathrm{~h}, 600 \mathrm{rpm}$ & 40,2 & 42,9 & 7,2 & 5,9 & 2,5 \\
$2 \mathrm{~h}, 600 \mathrm{rpm}$ & 46,0 & 37,0 & 8,8 & 3,3 & 3,4 \\
$4 \mathrm{~h}, 400 \mathrm{rpm}$ & 48,6 & 35,3 & 9,6 & 1,9 & 4,1 \\
$4 \mathrm{~h}, 800 \mathrm{rpm}$ & 34,0 & 47,8 & 6,1 & 7,9 & 1,3 \\
\hline
\end{tabular}

Quadro 8. Resultado do planejamento fatorial $2^{3}$ composto central para a extração de potássio da moscovita

\begin{tabular}{ccccc} 
Tempo (A) & Rotação $(\mathbf{B})$ & Dose $(\mathbf{C})$ & Extração $\mathbf{K}^{+}(\boldsymbol{\%})$ & Diâmetro Médio $(\boldsymbol{\mu m})$ \\
\hline-1 & -1 & -1 & 3,47 & 64,85 \\
1 & -1 & -1 & 3,54 & 43,67 \\
-1 & 1 & -1 & 8,21 & 25,75 \\
1 & 1 & -1 & 9,90 & 10,38 \\
-1 & -1 & 1 & 3,82 & 55,77 \\
1 & -1 & 1 & 3,68 & 52,45 \\
-1 & 1 & 1 & 5,82 & 22,95 \\
1 & 1 & 1 & 11,18 & 10,89 \\
-1 & 0 & 0 & 6,05 & 26,92 \\
1 & 0 & 0 & 10,22 & 14,53 \\
0 & -1 & 0 & 4,36 & 47,83 \\
0 & 1 & 0 & 9,19 & 11,22 \\
0 & 0 & -1 & 6,87 & 12,96 \\
0 & 0 & 1 & 6,71 & 16,43 \\
0 & 0 & 0 & 4,00 & 2,79 \\
0 & 0 & 0 & 6,89 & 3,20 \\
0 & 0 & 0 & 7,13 & 3,39 \\
0 & 0 & 0 & 7,01 & 3,33 \\
\hline
\end{tabular}




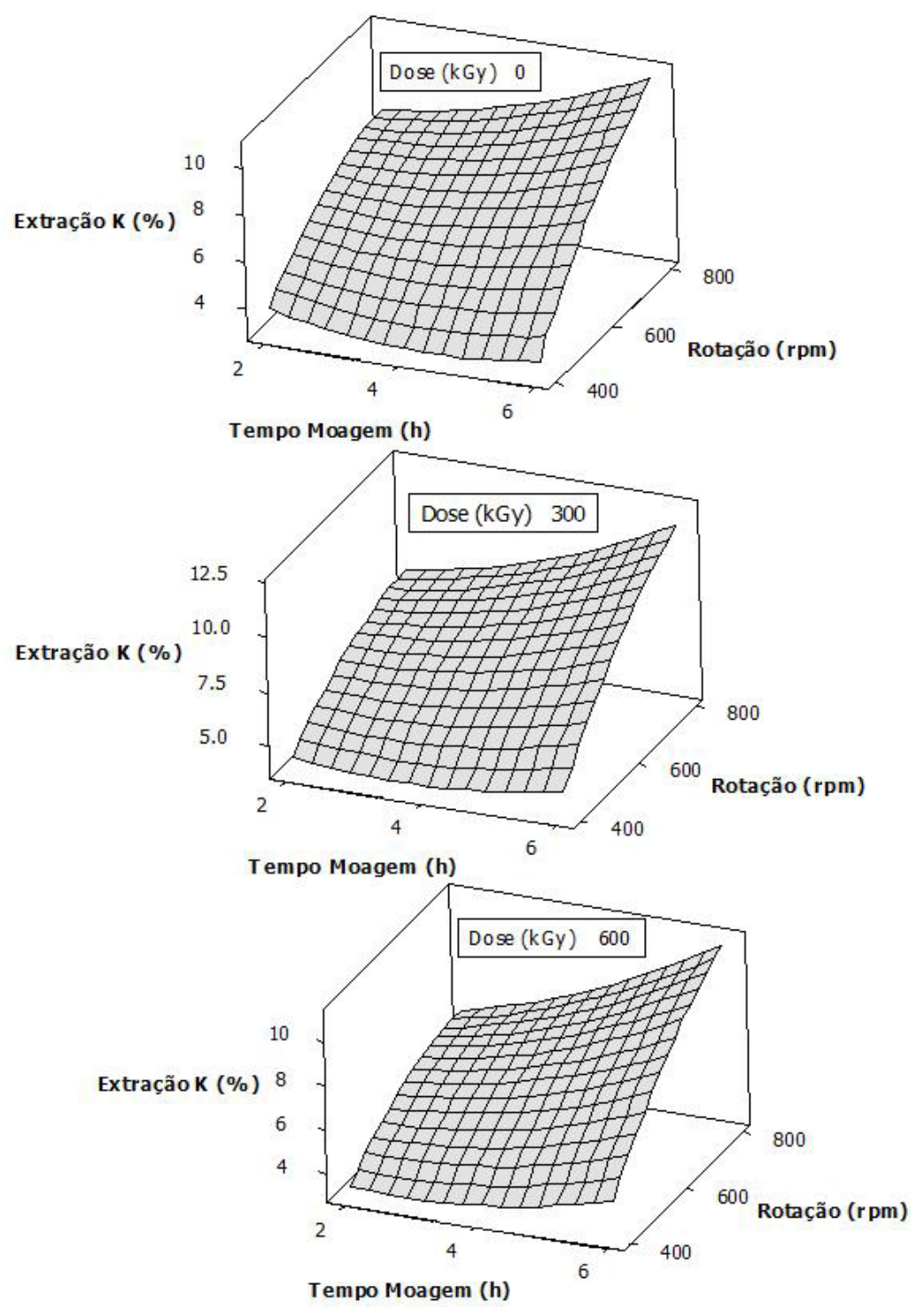

Figura 6. Efeito do tempo de moagem, da rotação e da dose sobre a extração de potássio.

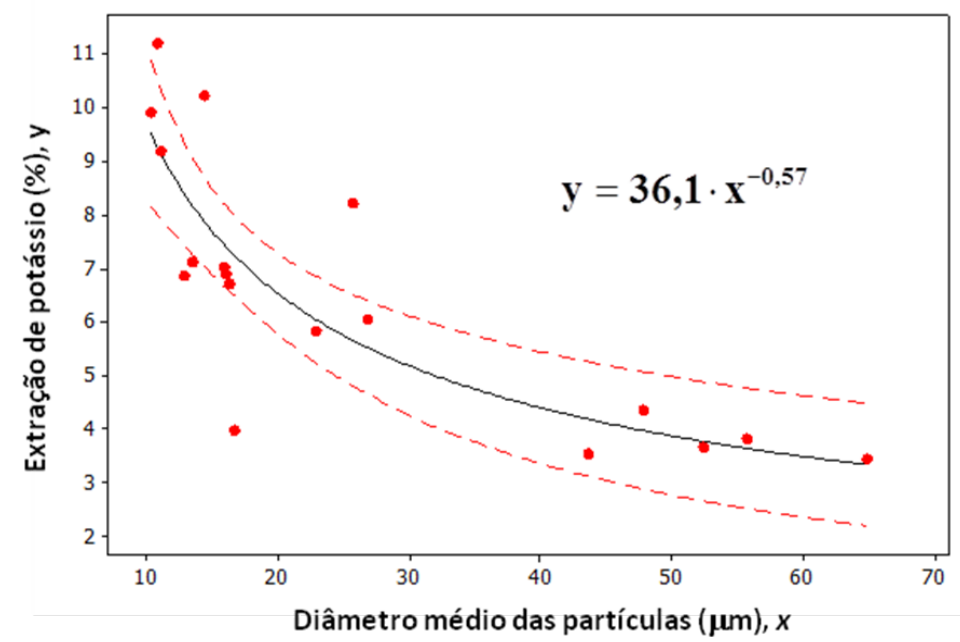

Figura 7. Efeito do diâmetro médio das partículas de moscovita sobre a extração de potássio (as curvas tracejadas são os intervalos de confiança-95\%). 
A tese de que a irradiação poderia aumentar a taxa de liberação de potássio devido à substituição do silício por alumínio na rede cristalina da moscovita não se sustentou de acordo com os resultados obtidos. Essa substituição provavelmente ocorre numa fração muito pequena nos sítios do silício para provocar algum efeito mensurável na taxa de liberação. Por outro lado, como esperado, a taxa de liberação de potássio aumentou com a diminuição do tamanho das partículas de moscovita. Porém, esse aumento não foi diretamente proporcional ao aumento da área superficial das partículas por unidade de volume. O valor absoluto expoente na equação (1) menor que 1 pode indicar inibição da taxa de liberação de potássio, provocado pela decomposição da moscovita ou pela presença das partículas de alumina, introduzidas pelo processo de moagem.

Estes resultados indicam que a diminuição da granulometria da moscovita para a faixa de $10 \mu \mathrm{m}$ ou menor, com o uso da moagem de alta intensidade, pode proporcionar um aumento substancial da taxa de liberação de potássio, tornando-a potencialmente viável para utilização na composição de solos para suprimento de potássio para a agricultura.

\section{CONCLUSÕES}

- Há uma liberação de potássio de $11,2 \%$ da moscovita, extraído por meio resina de troca iônica, após moagem de alta intensidade em moinho de bola do tipo planetário, com duração de 6 horas e 800 rpm. Essa liberação é o dobro daquela antes da moagem;

- Com a moagem de alta intensidade (800 rpm e $6 \mathrm{~h}$ ) obteve-se um tamanho médio da partícula de moscovita na faixa de 10 a $11 \mu \mathrm{m}$ (uma redução de 9 vezes em relação à moscovita pulverizada);

- Há um grande aumento do desgaste dos corpos moedores e dos recipientes do moinho com o aumento da rotação e do tempo de moagem, com a consequente contaminação da moscovita;

- A dose de irradiação gama até 600 kGy não influenciou a liberação de potássio da moscovita; e
- A extração de potássio aumenta com a diminuição do diâmetro médio das partículas de moscovita $(\mathrm{x})$ na proporção de $\mathrm{x}^{-0,57}$. Este resultado indica que a moscovita moída com granulometria até $10 \mu \mathrm{m}$ ou menor pode proporcionar um substancial aumento da taxa de liberação de potássio, tornando-a potencialmente viável para utilização na composição de solos para suprimento de potássio para a agricultura.

\section{AGRADECIMENTOS}

Ao CNPq (Conselho Nacional de Desenvolvimento Científico e Tecnológico), pelo financiamento desta pesquisa (Processo número 574734/2008-2).

\section{REFERÊNCIAS BIBLIOGRÁFICAS}

BARTHELMY, D. Mineralogy Database. 2010. Disponível em <http://webmineral.com $>$. Acesso em: 04/05/2011

FOTH, H.D. Fundamentals of Soil Sicence. Hoboken (NJ, EUA). John Wiley \& Sons, Inc. 1990. $8^{\text {th }}$ Edition. 384p.

GHOSH, D.C.; GHOSH, S.; MALIK, G.C. Effects of Potassium and Sulfur Fertilizers on Development and Yield of Groundnut on Coarse Textured Lateritic Soils of West Bengal. In: Potash Review, 2., 1995, Switzerland. International Potash Institute. Disponível em: <http://www.ipipotash.org/pdf/ review/9_1995_8.pdf $>$. Acesso em: 05/05/2011.

MALLARINO, A.P. and HIHASHI, S.L. Assessment of Potassium Supply for Corn by Analysis of Plant Parts. Soil Science Society of America Journal, Madison, v.73, n.6, p.21772183, 2009.

MARTINS, E.D.S, RESENDE, A.V., OLIVEIRA, C.G., FURTINI NETO, A.E. Materiais Silicáticos como Fontes Regionais de Nutrientes e Condicionadores de Solos. In: Agrominerais para o Brasil. Rio de Janeiro: Centro de Tecnologia Mineral, 2010, 26p. 
MORSHED, R.M., RAHMAN, M.M., RAHMAN, M.A., and HAMIDULLAH, A.T.M. Effect of Potassium on Growth and Yield of Soybean. Bangladesh, v.5, n.2, p.35-42, 2009.

NUNES, E.H., MELO, V., LAMEIRAS, F., LIZ, O., PINHEIRO, A., MACHADO, G., VASCONCELOS, W. Determination of the potential for extrinsic color development in natural colorless quartz. American Mineralogist, Chantilly, v.97, n.7, p.935-941, 2009.

OLIVEIRA, L.A.M. Potássio. In: Sumário Mineral 2009. Departamento Nacional de Produção Mineral. v.29, 2010.
RESENDE, A.V., MACHADO, C.T.T., MARTINS, E.S., NASCIMENTO, M.T., SENA, M.C., SILVA, L.C.R., LINHARES, N.W. Rochas Moídas como Fontes de Potássio para o Milho em Solo de Cerrado. Boletim de Pesquisa e Desenvolvimento 162. EMBRAPA. Planaltina (DF), Abril de 2006. 20p.

SILVA, F.D.C. Manual de Análises Químicas de Solos, Plantas e Fertilizantes. Brasília: EMBRAPA, 2009. 624p.

VALE. Projetos 2010. Disponível em: < http:// vale.com/pt-br/o-que-fazemos/mineracao/ potassio/projetos/paginas/default.aspx $>$ Acesso em: 29/12/2010. 